\title{
EL ENDECASÍLABO DACTÍLICO EN POESÍA POPULAR
}

\author{
José Domínguez CAPARrós
}

Resumen: Esta breve nota se centra en el uso que del romance popular asturiano ;Ay Juana, cuerpo garrido! se hace en las discusiones sobre el endecasílabo dactílico. Se estudian especialmente las cuestiones de tio métrico y textual que se manifiestan por las distintas actitudes de los teóricos que han utilizado este texto (Manuel Milá y Fontanals, Eduardo de la Barra, Marcelino Menéndez y Pelayo, y Julio Vicuña Cifuentes).

Palabras clave: Endecasílabo dactílico, romance, tratadistas de métrica, Milá, Menéndez y Pelayo, De la Barra, Vicuña

Abstract: This short note is about the use of the popular asturian ballad, ;Ay Juana, cuerpo garrido!, in the discusions of the dactylic line of eleven syllables in Spanish. Problems of metric and textual nature are specially taken into account focusing in the way the metrists (Manuel Milá y Fontanals, Eduardo de la Barra, Marcelino Menéndez y Pelayo, y Julio Vicuña Cifuentes) have used this text.

Key words: Dactylic line of eleven syllables, ballad, metrists, Milá, Menéndez y Pelayo, De la Barra, Vicuña 

os estudiosos del endecasílabo dactílico suelen comentar como ejemplo de tal verso en poesía popular el del romance asturiano titulado La Tentación. En esta nota nos proponemos aclarar y comentar varios aspectos relacionados con el uso que de tal poema se ha hecho en las discusiones sobre el mencionado endecasílabo. Pero antes de entrar en materia hay que hacer unas brevísimas precisiones de algo que tratamos mucho más extensamente en nuestra monografía, de próxima aparición, El moderno endecasílabo dactílico, anapéstico o de gaita gallega.

Primero, su definición. La del pionero de los estudios sobre este verso, Milá y Fontanals, sigue siendo válida:

El endecasílabo en que debemos ocuparnos tiene, como el sáfico, acento en la cuarta, pero lo tiene en la séptima en vez de la octava y es ventajoso (especialmente para el canto) que lo tenga en la primera ${ }^{1}$.

Por eso, se puede hablar, con Tomás Navarro Tomás, de una forma plena (acentos en 1. ${ }^{\mathrm{a}}, 4 .^{\mathrm{a}},{ }^{\mathrm{a}}{ }^{\mathrm{a}} \mathrm{y} 10 .^{\mathrm{a}}$ ) y una manifestación parcial (acentos en 4. $.^{\mathrm{a}}, 7 .^{\mathrm{a}}$ y 10. $\left.{ }^{\mathrm{a}}\right)^{2}$.

Segundo, su calificación. Bello -y después Eduardo de la Barra, J. Vicuña o T. Navarro Tomás- lo califica rítmicamente de

${ }^{1}$ Milá y Fontanals, Manuel: "Del decasílabo y endecasílabo anapésticos". Revista Histórica Latina, julio 1875, en Obras Completas, coleccionadas por Marcelino Menéndez y Pelayo, tomo V. Barcelona: Librería de Álvaro Verdaguer, 1893 , p. 326.

2 Navarro Tomás, Tomás: Métrica española. Madrid: Guadarrama, 1972, tercera edición corregida y aumentada, pp. 203-204. Varela Merino, Elena, Moíno Sánchez, Pablo, Jauralde Pou, Pablo: Manual de Métrica Española. Madrid: Editorial Castalia, 2005, pp. 193-195, precisan más los tipos de endecasílabo dactílico distinguiendo entre: puro (anapéstico), con acentos en $4 .^{\mathrm{a}}$ y $7 .^{\mathrm{a}} ;$ pleno, con acentos en $1 .^{\mathrm{a}},{ }^{\mathrm{a}}{ }^{\mathrm{d}}$ y $7 .^{\mathrm{a}} ;$ y corto, con acentos en $2 .^{\mathrm{a}}, 4 .^{\mathrm{a}}$ y $7 .^{\mathrm{a}}$. 
dactílico. Milá y Fontanals, seguido por Marcelino Menéndez y Pelayo y por Pedro Henríquez Ureña, lo consideró, en el primer estudio extenso de nuestra filología sobre este verso, como anapéstico. Marcelino Menéndez y Pelayo insiste en la relación con la gaita gallega, estudiada por Milá, y le asocia casi siempre el nombre de endecasílabo de gaita gallega.

Tercero, los teóricos. Milá y Fontanals, Menéndez y Pelayo, Eduardo de la Barra y Julio Vicuña Cifuentes son los autores que más atención han dedicado a un estudio de conjunto del verso, independientemente de muchísimas otras noticias que puedan encontrarse en los más diversos lugares.

Cuarto, sus usos. Suelen distinguirse dos empleos bien diferenciados de la estructura del endecasílabo antes descrita: aparición casual entre versos de otra estructura, como endecasílabos italianos (Garcilaso: Tus claros ojos, ¿a quién los volviste?; ¿Cómo pudiste tan pronto olvidarte ${ }^{3}$; Hinchen el aire de dulce armonía), versos de arte mayor o de Juan de Mena (Nebrija da como una de las posibilidades rítmicas de tal verso la del endecasílabo dactílico: Sabia en lo bueno, sabida en maldad), y versos fluctuantes de las canciones populares con ritmo de gaita gallega. Hay quien como Eduardo de la Barra lo encuentra también en la versificación épica medieval. El otro uso es el unifor$m e$, cuando el poema adopta como diseño de todos sus versos el de la estructura del endecasílabo dactílico.

Quinto, su uso independiente. Lo que nos interesa es el segundo uso, el uniforme, que, por lo que se refiere a la poesía culta, suele datarse a principios del siglo XVIII. Para el uso en poesía popular, los estudiosos han destacado la singularidad del romance en que nos vamos a centrar.

Contextualizado el lugar del objeto de nuestro trabajo entre los aspectos que abarca el análisis del endecasílabo dactílico, veamos qué se dice sobre el romance asturiano. Junto al conocido ejemplo de la letra popular de baile Tanto bailé a la puerta del cura / Tanto bailé que me dio calentura, dice Milá y Fontanals:

existe otro ejemplo que descubrió en Asturias y publicó en las Bellezas $y$ recuerdos de España el excelente escritor Quadrado. Este interesante

$\overline{3}$ Véase Navarro Tomás. T.: Métrica española, cit., p. 204. 
fragmento, ya por el metro, ya por la construcción poética, descubre íntimo enlace con la poesía popular gallega y aun por el último título con la antigua portuguesa. No hay necesidad de advertir que los dos primeros versos son octosílabos:

¡Ay Juana, cuerpo garrido!

¡Ay Juana, cuerpo lozano!

¿Dónde le dejas á tu buen amigo?

¿Dónde le dejas á tu buen amado?

- Muerto le dejo á la orilla del río,

Déjole muerto á la orilla del vado.

-- ¿Cuánto me das y volvértelo he vivo?

¿Cuánto me das y volvértelo he sano?

- Doyte las armas y doyte el rocino,

Doyte las armas y doyte el caballo ${ }^{4}$.

Obsérvese que los ocho versos que siguen a los dos primeros son endecasílabos dactílicos perfectos, pero hay que tener en cuenta que el adjetivo posesivo $t u$ (vv. 3 y 4) debe pronunicarse como tónico, según el uso asturiano, debilitando o anulando el acento en buen: dónde le déjas a tú buen amígo. La doble asonancia, en io (impares) y ao (pares), da unidad a la composición. Notemos que considera que el texto es un fragmento ${ }^{5}$.

${ }^{4}$ Milá y Fontanals, M.: “Del decasílabo...”, cit., p. 339.

${ }^{5}$ El texto citado por Milá está tomado de Quadrado, J. M.: Recuerdos y bellezas de España. Asturias y León. Madrid: Imprenta de Repullés, 1855, p. 239. Mila solamente corrige algún signo de apertura de admiración e interrogación que falta en los versos 1,2 y 8 , y el leísmo de la forma volvértele en los versos 7 y 8 , además de la coma tras das en estos mismos versos. También aquí J. M. Quadrado habla de "dos preciosos fragmentos" para introducir el texto que empieza Mañanita de San Juan / Cayó un marinero al agua, que va inmediatamente antes del que hemos reproducido. Curiosamente, Juan Menéndez Pidal, a quien nos vamos a referir pronto, edita, en 1885 , otra versión de estos romances dándoles el título de El Marinero y La Tentación respectivamente. Marceliono Menéndez y Pelayo reproduce también juntos los mismos dos romances y con los títulos que les da Juan Menéndez Pidal. Para las fuentes de esre romance, véase Busto Cortina, Juan: Catálogo índice de romances asturianos. Oviedo: Principado de Asturias, 1992, pp. 292-293. La versión más antigua está recogida en 1849, dictada por Pedro José Pidal y publicada por Durán, Agustín: "Apéndice al discurso preliminar", en Romancero General. Colección de romances castellanos anteriores al siglo XVIII. Tomo I, BAE, X. Madrid: Atlas, 1945, p. LXVI. Esta versión tiene diez versos, texto igual al de Quadrado, pero con una variante digna de notar en los versos 7 y 8, que siguen siendo endecasílabos dactílicos: ¿Cuánto 
Eduardo de la Barra, en 1895, afirma que hay muchos ejemplos de este verso en las canciones populares - no dice si casual entre otros o de manera uniforme-, pero sólo cita unos cuantos versos del texto que comentamos. Dice exactamente:

Puede el que quiera hacer amplia cosecha del mismo verso en las canciones populares, de ordinario modernizadas, sin que por eso pierdan su ritmo primitivo. Aquí solo traeremos a cuento uno de los viejos cantares asturianos, aquel que comienza:

"Ay, Juana, cuerpo garrido, / Ay Juana, cuerpo gentil"

Encuéntranse allí dáctilos de once sílabas tan graciosos como estos emparejados:

-Muerto le dejo a la orilla del rio,

Déjole muerto a la orilla del vado...

-Doyte las armas e doyte el rocino,

Doyte las armas e doyte el caballo ${ }^{6}$.

E. de la Barra no conoce la versión que en 1885 publicó Juan Menéndez Pidal, pues en ella los dos primeros versos, como veremos, también eran endecasílabos dactílicos que no habrían pasado inadvertidos al chileno. Sin embargo, sustituye en el segundo octosílabo del comienzo la palabra lozano por gentil y así destroza la rima asonante en ao de los versos pares del poema. Suprime en su ejemplo los versos 2 y 3, quizá por la dificultad que presenta la acentuación del adjetivo posesivo tu para la realización del ritmo dactílico, como hemos visto. Suprime igualmente los otros dos versos, 7 y 8 , que tienen una interrogación. Pero hay también una intervención de E. de la Barra en el texto que parece querer darle una nota de antigüedad: la sustitución de la conjunción y por $e$. Piensa que la canción es más antigua de lo que pudiera parecer por su forma modernizada, como insinúa en la observación general sobre las canciones populares que hemos copiado en la cita anterior. No dice de dónde toma el texto E. de

me das, volver he te le vivo? / ¿Cuánto me das volver he te le sano? En Agustín Durán se encuentra ya la idea de que se trata de fragmentos ( $\mathrm{p}$. LXV), al tiempo que edita los dos juntos, el Romance del marinero y el que titula Cantar antiguo ("¡Ay Juana, cuerpo garrido!”), recitados en 1849 -edición del tomo X de la BAE- por Pedro José Pidal, quien los había oído en su niñez.

${ }^{6}$ Barra, Eduardo de la: El endecasílabo dactílico. Rosario de Santafé: J. Ferrazini y Comp., 1895, p. 23. 
la Barra, pero podría ser del estudio de Milá -aunque afirma en otro lugar de su monografía (p. 65) que solo tiene noticias de este trabajo por Menéndez y Pelayo, pero que lo desconoce-, o del texto de 1855 de J. M. Quadrado, pero en este caso sería también Milá la fuente de información. ¿Conocía realmente el artículo de Milá, que había sido reeditado en 1893 por Menéndez y Pelayo en las Obras Completas de su maestro? Pudiera quizá también conocerlo por la edición de Agustín Durán, donde se leen ideas semejantes a las recogidas por De la Barra acerca de su carácter antiguo y su forma moderna de lenguaje.

En el tomo X de su Antología de poetas líricos (1913), en la sección dedicada a los "Romances tradicionales de Asturias", Marcelino Menéndez y Pelayo reproduce el siguiente texto:

\section{LA TENTACIÓN}

— Ay, probe Xuana de cuerpo garrido!

¡Ay, probe Xuana de cuerpo galano! ¿Dónde le dexas al tu buen amigo? ¿Dónde le dexas al tu buen amado?

- Muerto le dexo a la orilla del río, muerto le dexo a la orilla del vado! ¿Cuánto me das, volverételo vivo? ¿Cuánto me das, volverételo sano? -Doyte las armas y doyte el rocino, doyte las armas y doyte el caballo.

-No he menester ni armas ni rocino, no he menester ni armas ni caballo.... ¿Cuánto me das, volverételo vivo? ¿Cuánto me das, volverételo sano?

Después de citar a Milá y Fontanals ${ }^{8}$, continúa su comentario:

${ }^{7}$ Menéndez y Pelayo, Marcelino: Antología de poetas líricos castellanos. Tomo X. Madrid: Librería de Hernando y C.,, 1913 , p. 441. Puede verse también el volumen IX, p. 259, de su Antología de poetas líricos espanoles (Parte segunda: Los romances viejos IV. Capitulo: Suplementos a la "Primavera y flor de romances". Epígrafe: Romances tradicionales de Asturias) en Menéndez y Pelayo, M.: Obras completas. Madrid: CSIC, 1940-1966.

${ }^{8}$ Copia las siguientes palabras de Milá, que hemos visto en el texto previo a los versos: Este interesante fragmento, ya por el metro, ya por la construcción poética, descubre intimo enlace con la poesía popular gallega, 
Está compuesto, en efecto, en aquel género de endecasílabo que vulgarmente se denomina de gaita gallega y que sirve para acompañar el ritmo de la muñeira. Milá, que le estudió detenidamente, tanto en sí mismo como en sus relaciones con el verso decasílabo, le llamó endecasílabo anapéstico. Su aparición en la poesía popular castellana es un fenómeno singular, aun en Asturias misma, y hasta ahora no se ha presentado más ejemplo que éste.

El texto de Menéndez y Pelayo, respecto del reproducido por Milá, presenta dos notas importantes: los dos primeros versos ya no son octosílabos, sino endecasílabos dactílicos perfectos; hay cuatro versos más. Si bien los versos 13 y 14 son repetición de los versos 7 y 8 , los versos 11 y 12 son nuevos y además no son endecasílabos dactílicos. Para ser endecasílabos tendrían que hacer hiato (dialefa) en $n i$ / armas, y llevan el acento en la $6 .^{\text {a }}$, en lugar de la 7. ${ }^{\mathrm{a}}$, por lo que no son dactílicos. Destaquemos, por último, en el comentario del santanderino, la llamada de atención sobre la singularidad de este ejemplo de endecasílabo dactílico en la poesía popular.

La fuente de este texto es la obra de Juan Menéndez Pidal, Poesía popular. Colección de los viejos romances que se cantan por los asturianos (1885). El mismo Menéndez y Pelayo, en la Advertencia preliminar, nos habla del "joven y aventajado escritor asturiano, D. Juan Menéndez Pidal” y de su obra, cuyo contenido describe así:

Los romances llegan a 98, aunque algunos son variantes del mismo tema, y otros no merecen estrictamente la calificación de populares. Pero la mayor parte lo son, sin género de duda, y algunos merecen figurar al lado de los más bellos de las antiguas colecciones. Con el beneplácito del Sr. Menéndez Pidal, a quien damos mil gracias por esta prueba de cariñosa amistad, reproducimos aquí todos los que, a nuestro juicio, presentan rasgos de poesía primitiva, incluyendo no solamente los impresos en 1885, sino algunos inéditos hasta ahora, que el mismo colector ha recogido en posteriores excursiones y que liberalmente nos ha facilitado 9 .

y aun por el último título con la antigua portuguesa. Menéndez y Pelayo, M., ibid., p. 441.

${ }^{9}$ Menéndez Y Pelayo, Marcelino: Antología..., cit., p. 18. 
La única diferencia notable entre los dos textos (el de J. Menéndez Pidal y el de $\mathrm{M}$. Menéndez y Pelayo) está en el verso 6, que Juan Menéndez Pidal copia así: muerto dexole a la orilla del vado. Evidentemente esta forma (acentos en 1. a, 3. $.^{\mathrm{a}}, 7 .^{\mathrm{a}}$ y $10 .^{\mathrm{a}}$ ) no es la de ningún tipo de endecasílabo, ni italiano ni dactílico. Menéndez Pelayo corrige entonces en paralelo con el verso anterior y dice: muerto le dexo a la orilla del vado, que sí es un endecasílabo dactílico perfecto. Pero J. Menéndez Pidal también había advertido la equivocación y en la lista de erratas, al final del libro, corrige: déxole muerto en lugar de muerto déxole, y entonces el endecasílabo es perfecto dactílico. Menéndez Pelayo detectó el error, pero no se atuvo a la fe de erratas de J. M. Pidal. En la anotación de Menéndez y Pelayo a este romance y al anterior de la colección, El Marinero, hay coincidencia de algunos datos, que por lo que a nosotros nos interesa, la métrica, se ve en las siguientes palabras de Juan M. Pidal:

La Tentación es un romance singular de Asturias, y aun entre los de esta región, por la metrificación desusada que en él se emplea.

Por lo demás, Juan M. Pidal sostiene que los dos romances, El Marinero y La Tentación, "son fragmentos de otros más completos". También nos dice que este romance, recogido en Grado, fue recitado por Teresa Fernández (a) La Cana, de 80 años y vecina de Santianes de Molenes ${ }^{10}$.

M. Menéndez y Pelayo prefiere esta versión más amplia y uniforme (todos los versos son endecasílabos) a la recogida por J. M. Quadrado, publicada en 1855, que es la comentada por Milán ${ }^{11}$.

Julio Vicuña Cifuentes copia el texto tomándolo de Juan Menéndez Pidal, citando el título de la obra y la página (245) en que aparece. Destaca su singularidad:

\footnotetext{
${ }^{10}$ Menéndez Pidal, Juan: Poesía popular: colección de los viejos romances que se cantan por los asturianos. Madrid: Hijos de J. A. García, 1885, pp. 332 y 355.

${ }^{11}$ En la misma advertencia preliminar de este tomo, Menéndez y Pelayo se refiere a J. M. Quadrado con "cariñoso respeto" y lo considera "español de los más memorables de nuestro siglo en virtud, entendimiento y ciencia”. Véase Antología...,cit., p. 15.
} 
Notable sobre todo lo demás que yo conozco, compuesto en este metro, en la poesía popular castellana, es el fragmento de romance de doble asonante, recogido en Asturias por don Juan Menéndez Pidal ${ }^{12}$.

El texto de Vicuña introduce una nota que es digna de ser destacada: acentúa la palabra armás en los versos 11 y 12 . Así se soluciona el problema métrico que presentaban estos dos versos; de esta forma se hacen dactílicos perfectos, si se hace el hiato (dialefa) $n i$ / armas:

-No he menester ni armás ni rocino no he menester ni armás ni caballo...

Vicuña, pues, lee como estricto tratadista de métrica. Supone el punto culminante de la lectura métrica de este texto, que se ha convertido en el ejemplo canónico de endecasílabo dactílico en poesía popular. Se puede establecer una relación entre la historia del texto y la lectura métrica del mismo. A la consagración como ejemplo singular dentro de la teoría del endecasílabo dactílico por parte de M. Milá y Fontanals, sigue E. de la Barra, quien lo lee con ojos de metricista y suprime en su ejemplificación los versos que le estorban (los dos octosílabos primeros, y los que exigen acentuación en el adjetivo $t u$ ). La nueva versión aportada por Juan Menéndez Pidal soluciona el problema de la uniformidad métrica -todos los versos son endecasílabos-, pero añade cuatro versos entre los que se encuentran dos que plantean el problema rítmico de no ajustarse sin dificultad al ritmo dactílico. Es éste un problema que detecta Julio Vicuña Cifuentes y trata de solucionar proponiendo el desplazamiento del acento en la palabra armas.

\section{Bibliografía}

BARRA, E. de la: El endecasílabo dactílico. Rosario de Santafé: J. Ferrazini y Comp., 1895.

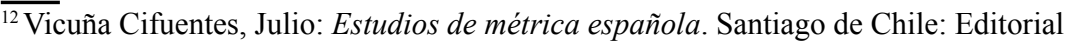
Nascimento, 1929, pp. 130-131. 
Busto Cortina, J.: Catálogo índice de romances asturianos. Oviedo: Principado de Asturias, 1992.

DuRÁn, A.: “Apéndice al discurso preliminar", en Romancero General. Colección de romances castellanos anteriores al siglo XVIII. Tomo I, BAE, X. Madrid: Atlas, 1945.

HenríQuez Ureña, P.: Estudios de versificación española. Buenos Aires: Universidad, 1961.

Menéndez y Pelayo, M.: Antología de poetas líricos castellanos. Tomo X. Madrid: Librería de Hernando y C., 1913.

-Obras completas. Madrid: CSIC, 1940-1966. (Menéndez Pelayo digital, CD-ROM, Caja Cantabria, Obra Social y Cultural, 1999).

MenÉndez Pidal, J.: Poesía popular: colección de los viejos romances que se cantan por los asturianos. Madrid: Hijos de J. A. García, 1885.

Milá y Fontanals, M.: "Del decasílabo y endecasílabo anapésticos". Revista Histórica Latina, julio 1875, en Obras Completas, coleccionadas por Marcelino Menéndez y Pelayo, tomo V. Barcelona: Librería de Álvaro Verdaguer, 1893, pp. 324-344.

NaVARro Tomás, T.: Métrica española. Madrid: Guadarrama, 1972, tercera edición corregida y aumentada.

QuAdRADO, J. M.: Recuerdos y bellezas de España. Asturias y León, por F. J. Parcerisa, escrita y documentada por J. M. Quadrado. Madrid: Imprenta de Repullés, 1855 .

Varela Merino, E.; Moíño Sánchez, P.; Jauralde Pou, P.: Manual de Métrica Española. Madrid: Editorial Castalia, 2005.

Vicuña Cifuentes, J.: Estudios de métrica española. Santiago de Chile: Editorial Nascimento, 1929. 